\title{
Renegotiations in the Greenhouse
}

\author{
Hans-Peter Weikard • Rob Dellink • Ekko van Ierland
}

Accepted: 7 October 2009 / Published online: 5 November 2009

(C) The Author(s) 2009. This article is published with open access at Springerlink.com

\begin{abstract}
International climate policies are being shaped in a process of ongoing negotiations. This paper develops a sequential game framework to explore the stability of international climate agreements allowing for multiple renegotiations. We analyse how the incentives to reach an international climate agreement in the first period will be impacted by the prospect of further negotiations in later periods and by the punishment options related to renegotiations. For this purpose we introduce a dynamic model of coalition formation with twelve world regions that captures the key features of the climate-economy impacts of greenhouse gas emissions. For a model with one round of renegotiations we find that a coalition of China and the United States is the unique renegotiation proof equilibrium. In a game with more frequent renegotiations we find that the possibility to punish defecting players helps to stabilise larger coalitions in early stages of the game. Consequently, several renegotiation proof equilibria emerge that outperform the coalition of China and USA in terms of abatement levels and global payoff. The Grand Coalition, however, is unstable.
\end{abstract}

Keywords International climate agreements $\cdot$ Self-enforcing international environmental agreements $\cdot$ STACO model $\cdot$ Coalition formation with renegotiation

JEL Classification C73 $\cdot$ D74 $\cdot$ Q54

H.-P. Weikard $(\bowtie) \cdot$ R. Dellink · E. van Ierland

Environmental Economics and Natural Resources Group, Wageningen University, Hollandseweg 1, 6706 KN, Wageningen, The Netherlands

e-mail: hans-peter.weikard@wur.nl

R. Dellink

Institute for Environmental Studies, VU University Amsterdam, Amsterdam, The Netherlands 


\section{Introduction}

The control of greenhouse gases (GHGs) is a global public benefit. In the absence of global institutions underprovision of GHG abatement is expected and well understood. Less understood are conditions under which effective international climate agreements (ICAs) might emerge and which mechanisms might help to stabilise agreements. Recent literature on the stability of ICAs has focused on 'once and forever' models of negotiations, e.g. Hoel (1992), Carraro and Siniscalco (1993), Botteon and Carraro (1997), and Finus et al. (2006). However, the Conference of Parties meetings of the UNFCCC clearly illustrate that negotiating GHG emission controls is a process rather than a matter of striking an agreement. Furthermore, as the commitment period 2008-2012 agreed upon in the Kyoto protocol has started, there is a need to look ahead. Hence, the formation of ICAs is probably best understood in a sequential game framework.

The starting point of our analysis is that the prospect of renegotiations at a later stage might change the incentives to join a coalition and, therefore, it might change participation at an earlier stage. In this paper we examine whether the possibility of renegotiations hamper or help the formation of stable coalitions, and whether renegotiations will lead to agreements with higher or lower levels of abatement. The stability concept frequently used in coalition formation games is that of internal and external stability where no coalition member has an incentive to leave and no player outside the coalition has an incentive to join (d'Aspremont et al. 1983). This concept of stability is, however, no longer adequate in a game with renegotiations. As we study a sequential game we employ the equilibrium concept of Renegotiation Proof Equilibrium (RPE). The initial idea was developed by Bernheim (1987), Bernheim and Ray (1989), and Farrell and Maskin (1989). It has been applied to study international environmental agreements by Finus and Rundshagen (1998) in a two-player game. In our context a RPE is a sequence of coalitions ${ }^{1}$ (or ICAs) such that (i) the path of play is subgame perfect, i.e. a Nash equilibrium is played at every subgame, and (ii) there is no subgame where a Pareto dominated Nash equilibrium is played. Subgame perfectness ensures that a player who defects from an equilibrium can be punished in the subsequent play of the game. In order to be credible, the punishment path of play must be such that no player has an incentive to deviate, i.e. the punishment will be carried out if a player deviates. Pareto dominated equilibria are ruled out because they would not survive renegotiation.

The topic of renegotiations has attracted a lot of attention in the recent literature on international environmental agreements. Barrett (1994, 1999) considers an infinitely repeated game. For such games, according to the folk theorem, the full cooperative outcome is generally supported by an equilibrium if discount rates are sufficiently close to zero (Fudenberg and Maskin 1986). The folk theorem applies when players can commit to some future path of play. If a commitment mechanism is lacking, renegotiations limit the possibility of credible punishment of free-rider behaviour. Hence, Barrett $(1994,1999)$ finds that infinitely repeated play does not guarantee full participation in international environmental agreements. Barrett's (1999) model has recently been extended by Asheim et al. (2006). They show that two regional agreements may outperform a single global agreement when large global coalitions cannot be stabilised. Na and Shin (1998) consider coalition formation with uncertain environmental benefits. Analysing a three-country, two-period model where new information becomes available in the second period they argue that new information may be detrimental to coalition stability. While a coalition of three countries, which are assumed to be identical ex ante, is stable, the coalition might break apart when information becomes

1 We refer to the situation where no agreement is formed and all players are singletons as a 'trivial' coalition. 
available revealing differences between countries. Rubio and Ulph (2002) examine coalition stability in a two-period model with a stock pollutant. Ulph (2004) and Kolstad (2007) further extend this model type to examine stability of ICAs under uncertainty and learning. The later models, unlike $\mathrm{Na}$ and Shin's model, are general with respect to the number of countries. Recently Rubio and Ulph (2007) and De Zeeuw (2008) have studied difference games of coalition membership in an infinite time horizon model. De Zeeuw uses farsighted stability as the solution concept. Rubio and Ulph's (2007) work is closest to our study. Their model and ours are both cartel games, i.e. it is assumed that the coalition formed is unique. Rubio and Ulph employ the solution concept of internal and external stability; we use a refinement of the same solution concept. There are two major differences, however. Rubio and Ulph work with a model with identical players and an infinite time horizon. Our model allows for heterogeneous players but the time horizon is finite. The latter allows us to employ backward induction. Rubio and Ulph find that coalition membership declines over time. Although this finding concurs with our results, the reasons for this finding are very different. This will be explained in more detail below.

Common to all these modelling approaches is, however, the assumption that all countries are identical, at least ex ante. This is a serious limitation for most practical applications of models of coalition stability and in particular for models of ICAs. ${ }^{2}$ There are two important motives to relax the assumption of identical countries. First, differences in abatement cost and benefits can induce cooperation as cheap abatement options can be better exploited. Second, asymmetry makes transfers effective that further help to stabilise agreements. Applied modelling approaches have employed integrated assessment models to obtain simulation results for heterogeneous players. Ciscar and Soria (2002), for example, have considered a sequential game of the formation of climate policies, but they do not consider coalition formation. In an empirically rich model with 26 regions Babiker (2001) finds that a coalition of OECD countries is not stable, but he cannot provide general insights in the existence of stable coalitions. A systematic screening for stable climate agreements has been conducted by Eyckmans and Tulkens (2003) who check stability for all 56 coalitions in a 6-regions model. Finus et al. (2006) use a larger 12-regions model to examine stability of ICAs. However, these latter approaches use a one-shot game model. Germain et al. (2003) use a dynamic model to explore core-stability. However, their analysis is confined to three regions.

What is lacking in the literature, however, are dynamic models of coalition formation that allow for heterogeneous players. Hence, this paper aims at filling a gap between the theoretical models (with general results and identical players) and empirical models (which allow for different costs and benefits of abatement of GHGs across regions, but which give little general insight in the stability of ICAs). Note that we leave the study of the impact of uncertainty and learning to future work. ${ }^{3}$ The merit of our model is that we present a dynamic GHG abatement game with an empirically relevant specification, asymmetric players and renegotiations.

We develop a sequential game where at each stage (commitment period) the players (regions) announce whether they join a unique international climate coalition or not. ${ }^{4}$ Then, for given membership of the ICA, the ICA and the singletons choose abatement efforts to maximise their respective net benefits (cf. Chander and Tulkens 1995). We identify the

\footnotetext{
2 How different incentives to join an ICA do in fact influence coalition membership, is demonstrated by Weikard et al. (2006) and McGinty (2007)

3 Dellink et al. (2008) is a starting point in the domain of applied modelling.

4 Due to computational complexity we do not consider multiple coalitions in our model with renegotiations. See Sáiz et al. (2006) for an analysis of multiple coalitions in a one-shot coalition formation game.
} 
renegotiation proof equilibria for a finite sequential game, which reflects the fact that fossil fuels - the major source of GHGs - are depletable. We extend the Stability of Coalitions model (STACO) introduced by Finus et al. (2006) and refined by Nagashima et al. (2009). STACO is a 12-regions integrated assessment model that consists of abatement and damage costs modules. STACO calculates the pay-offs of all possible coalitions and performs single-deviation stability checks. Details of the calibration of STACO are described in Sect. 3 below. We investigate the impact of the frequency of renegotiations, ranging from two to five over our time horizon of 100 years and identify renegotiation proof sequences of ICAs.

Our findings can be summarised as follows. If there is no or just one round of renegotiations, i.e. not more than two commitment periods, we have a unique RPE consisting of USA and China. The uniqueness of the equilibrium does not allow for any punishment. With more than two commitment periods we find multiple equilibria so that threats of punishment can be installed. A region that is supposed to cooperate in an equilibrium, but free-rides, can be punished by playing the RPE that gives the worst payoff to that region in the subgame that follows.

The paper is organised as follows. Section 2 presents our model of negotiations and renegotiations on greenhouse gas emissions reduction. Section 3 provides the calibration of the STACO model. Section 4 presents results for the one-shot game as a benchmark and examines games with multiple negotiation rounds. We consider the effects of timing and frequency of renegotiations. Section 5 concludes.

\section{The Game}

We consider a game with a finite number $R(1 \leq R<\infty)$ of renegotiation stages where a cartel formation game with open membership is the stage game. At each stage $r=1, \ldots, R$ players decide whether or not to join a unique coalition (the cartel). Then the coalition and the remaining players simultaneously set their GHG abatement levels. Our game is not a repeated game as the stage games are not identical. This is due to the fact that we allow for growth in the economy and technical progress leading to a reduction of abatement costs over time. More formally, let $N=\{1,2, \ldots, n\}$ be a set of players (regions). We adopt a discrete time model with a finite planning horizon $T$. Periods are denoted by $t=1,2, \ldots, T$. Every player $i$ chooses whether or not to sign an ICA at an initial stage $(r=1$ and $t(r)=1)$ and at each renegotiation stage $r=2, \ldots, R$. In what follows we label the initial negotiation also 'renegotiation'. Hence $r \in\{1, \ldots, R\}$ and we can denote a moment of renegotiation as $t(r) \in\{1, \ldots, T\}$. There are $R \leq T$ renegotiations. The model allows for multiple renegotiations at arbitrary renegotiation times.

The stage game consists of a membership game followed by an abatement game. In the membership game, at each stage $r=1, \ldots, R$ each region $i \in N$ adopts a strategy $\sigma_{i, r} \in$ \{no,yes\}, where $\sigma_{i, r}=$ no means that $i$ is not joining the coalition at stage $r$ and $\sigma_{i, r}=$ yes means that $i$ is joining the coalition at stage $r$. This membership game determines a coalition $K^{r} \subseteq N$ that forms at time $t(r)$.

The membership game is followed by an abatement game. We assume that each region $i$ has a path of baseline emissions $\left(\bar{e}_{i, 1}, \ldots, \bar{e}_{i, T}\right)$ specifying uncontrolled emissions $\bar{e}_{i, t}$ at each time $t$ up to the planning horizon $T$. For ease of reference we denote such paths by $\left\langle\bar{e}_{i}\right\rangle_{1}^{T} \equiv\left(\bar{e}_{i, 1}, \ldots, \bar{e}_{i, T}\right)$. Each player adopts an abatement path (pollution control strategy) $\left\langle q_{i}\right\rangle_{1}^{T} \equiv\left(q_{i, 1}, \ldots, q_{i, T}\right)$ from the set of feasible abatement paths. A path is feasible if for all regions $i \in N$, region $i$ 's abatement never exceeds its baseline emissions, i.e. $q_{i, t} \in\left[0, \bar{e}_{i, t}\right]$ for all $t$. The abatement path is determined in a sequence of decisions at times $t(r), r=1, \ldots, R$. For example, if we have three renegotiation stages, then $R=3$. Suppose 
renegotiation periods are $t(1)=1, t(2)=s$ and $t(R)=s^{\prime}$, then the relevant partition of the abatement path is written as

$$
\left\langle q_{i}\right\rangle_{1}^{T}=\left(\left\langle q_{i}\right\rangle_{1}^{s-1},\left\langle q_{i}\right\rangle_{s}^{s^{\prime}-1},\left\langle q_{i}\right\rangle_{s^{\prime}}^{T}\right) .
$$

For the costs and benefits of abatement we consider that greenhouse gas abatement is a pure public good. Each region receives benefits $B_{i}$ from global abatement $\langle q\rangle_{1}^{T} \equiv\left\langle\sum_{i \in N} q_{i}\right\rangle_{1}^{T}$ and incurs costs $C_{i}\left(\left\langle q_{i}\right\rangle_{1}^{T}\right)$ for own abatement. These benefits and costs determine a gross payoff before transfers. Denoting the vector of regional abatement levels by $\langle\boldsymbol{q}\rangle_{1}^{T} \equiv\left(\left\langle q_{1}\right\rangle_{1}^{T}, \ldots,\left\langle q_{n}\right\rangle_{1}^{T}\right)$ the gross payoff can be written as

$$
\pi_{i}\left(\langle\boldsymbol{q}\rangle_{1}^{T}\right)=B_{i}\left(\langle q\rangle_{1}^{T}\right)-C_{i}\left(\left\langle q_{i}\right\rangle_{1}^{T}\right) .
$$

We assume that members of a given coalition $K^{r}$ formed at time $t(r)$ will adopt abatement paths to maximise the joint payoff of the coalition. Non-members seek to maximise their own payoff. This defines a difference game played by the coalition and the singleton players. In Appendix 1 we show that the abatement game has a unique interior solution for the STACO specification of benefit and cost functions (cf. Sect. 3) ${ }^{5}$ This solution of the stage $r$ abatement game when coalition $K^{r}$ is formed is denoted by $\left\langle\left. q_{1}^{K^{r}}\right|_{t(r)} ^{t(r+1)-1}, \ldots,\left\langle\left. q_{n}^{K^{r}}\right|_{t(r)} ^{t(r+1)-1}\right.\right.$. The uniqueness of the solution allows us, for convenience, to transform gross payoffs defined on the domain of stage $r$ abatement paths $\pi_{i}^{r}\langle\boldsymbol{q}\rangle_{t(r)}^{t(r+1)-1}$ to payoffs defined on the domain of coalitions. Furthermore, we assume that a coalition $K^{r} \subseteq N$ can arrange financial transfers $F_{i}\left(K^{r}\right)$ to redistribute gross payoffs between members. We require that $\sum_{i \in K} F_{i}\left(K^{r}\right)=0$ and $F_{j}\left(K^{r}\right)=0$ for $j \notin K^{r}$. We obtain, then, a stage $r$ valuation function that gives the payoff after transfers for every player and for every stage $r$ coalition.

$$
v_{i}^{r}\left(K^{r}\right) \equiv B_{i}\left(\left\langle\left. q^{K^{r}}\right|_{t(r)} ^{t(r+1)-1}\right)-C_{i}\left(\left\langle\left. q_{i}^{K^{r}}\right|_{t(r)} ^{t(r+1)-1}\right)+F_{i}\left(K^{r}\right) .\right.\right.
$$

Hence, the sequential game we specify has $R$ stages where at every stage $r$ a $n$-player membership game is played, followed by $n-\left|K^{r}\right|+1$-player abatement game where the coalition payoff is distributed among its members.

The game is solved by backward induction. Consider the renegotiations at times $t(1), \ldots, t(r), \ldots, t(R)$. At the time of the final renegotiation $t(R)$ there is an inherited stock of GHGs resulting from past emissions. Benefits from abatement depend on the stock of GHGs. In general this precludes a simple application of backward induction as the game in the final stage depends on the path of play in earlier stages due to the stock pollutant. In the STACO specification, however, although benefits in later stages depend on stock of GHGs and, therefore, the earlier path of play, marginal benefits are independent of the stock of GHGs. In this setting it is possible to determine the Nash equilibrium abatement path adopted at the final renegotiation stage, $\left\langle\left. q_{i}^{K^{R}}\right|_{t(R)} ^{T}\right.$.

Next, given the payoffs for all coalitions $K^{R} \subseteq N$ we determine the equilibria of the membership game. At the final stage we have a one-shot game where the standard definitions of stability apply (cf. d'Aspremont et al. 1983):

5 This type of solution has been called 'Partial Agreement Nash Equilibrium' by Chander and Tulkens (1995). Coalition members have signed a binding agreement. The coalition and the remaining singleton players play a Cournot-Nash game. 
Internal stability: A coalition $K^{R}$ is internally stable if and only if $v_{i}^{R}\left(K^{R}\right) \geq v_{i}^{R}\left(K^{R} \backslash\{i\}\right)$, for all $i \in K^{R}$.

External stability: A coalition $K^{R}$ is externally stable if and only if $v_{i}^{R}\left(K^{R}\right) \geq v_{i}^{R}\left(K^{R}\right.$ $\cup\{i\}$ ) for all $i \in N \backslash K^{R}$.

Stability: A coalition $K^{R}$ is stable if and only if it is internally and externally stable.

Obviously, the set of stable coalitions coincides with the set of (subgame perfect) Nash equilibria of the stage- $R$ game. Renegotiation proofness requires the following:

Renegotiation Proof Equilibrium: A sequence of coalitions is a RPE if and only if (i) the corresponding strategy profiles are a subgame perfect equilibrium and (ii) in every subgame the equilibrium outcome is Pareto undominated by any other equilibrium outcome of the subgame.

In general, we denote the set of RPE of the $r$ subgame by $\Psi^{r}$. Typical elements of $\Psi^{r}$ are sequences of coalitions denoted by $\psi^{r}=\left(K^{r}, \ldots, K^{R}\right)$. Consider a sequence $\psi^{r} \in \Psi^{r}$. We will write the valuation of the $r$ subgame as $V_{i}^{r}\left(\psi^{r}\right) \equiv v_{i}^{r}\left(K^{r}\right)+\cdots+v_{i}^{R}\left(K^{R}\right)$.

Now consider the renegotiation at an earlier stage $r<R$. We have to distinguish two situations. If the RPE of the $r+1$ subgame is unique, i.e. $\Psi^{r+1}$ contains a single element, backward induction is straightforward to apply. In this case, at time $t(r)$ each region knows that it will receive the unique RPE payoff of the $r+1$ subgame at stage $r+1$. Then, for a given coalition $K^{r}$ formed at stage $r$ the relevant payoffs are

$$
v_{i}^{r}\left(K^{r}\right)+V_{i}^{r+1}\left(\psi^{r+1}\right)=\pi_{i}^{r}\left(\left\langle\left.\boldsymbol{q}^{K^{r}}\right|_{t(r)} ^{t(r+1)-1}\right)+F_{i}\left(K^{r}\right)+V_{i}^{r+1}\left(\psi^{r+1}\right) .\right.
$$

The first order conditions to determine the Nash equilibrium stage $r$ abatement path $\left\langle\left.\boldsymbol{q}^{K^{r}}\right|_{t(r)} ^{t(r+1)-1}\right.$ are independent of earlier play as discussed before. Since there is a unique equilibrium of the $r+1$ subgame, later play cannot affect the decision at stage $r$ either.

If the $r+1$ subgame equilibrium is not unique, we have to consider the set of RPE, $\Psi^{r+1}$. In this case, the subgame perfect equilibria of the $r$ subgame may include equilibria where membership of player $i$ is induced by the threat that an equilibrium which is bad for $i$ will be played in the continuation game. Denote by $w_{i}^{r+1}$ the worst equilibrium path of play for player $i$, such that $V_{i}^{r+1}\left(\psi^{r+1}\right) \geq V_{i}^{r+1}\left(w_{i}^{r+1}\right)$ for all $\psi^{r+1} \in \Psi^{r+1}$. Then a coalition $K^{r}$ followed by $\psi^{r+1}$ is a subgame perfect equilibrium of the stage $r$ subgame if and only if for all $i \in K^{r}$

$$
v_{i}^{r}\left(K^{r} \backslash\{i\}\right)-v_{i}^{r}\left(K^{r}\right) \leq V_{i}^{r+1}\left(\psi^{r+1}\right)-V_{i}^{r+1}\left(w_{i}^{r+1}\right)
$$

and for all $i \in N \backslash K^{r}$

$$
v_{i}^{r}\left(K^{r} \cup\{i\}\right)-v_{i}^{r}\left(K^{r}\right) \leq V_{i}^{r+1}\left(\psi^{r+1}\right)-V_{i}^{r+1}\left(w_{i}^{r+1}\right) .
$$

Equation (4) requires that the gain a coalition member receives from defecting from coalition $K^{r}$ at stage $r$ must be no greater than the loss from a punishment in the form $w_{i}^{r+1}$ being played instead of $\psi^{r+1}$. Equation (5) requires that the gain of a singleton player from entering coalition $K^{r}$ must be no greater than the loss from a punishment in the form of $w_{i}^{r+1}$ being played instead of $\psi^{r+1}$ from stage $r+1$ onwards. Notice that the punishment play $w_{i}^{r+1}$ is in fact a credible punishment, because, by definition, $w_{i}^{r+1}$ is a RPE. As an RPE, $w_{i}^{r+1}$ is Pareto undominated and, hence, there must be at least one player who does not have a better option than to play $w_{i}^{r+1}$ and, therefore, the punishment will be carried out. Equations (4) and (5) are generalisations of the notions of internal and external stability, respectively. 
The set of RPE of the stage- $r$ subgame are the subgame perfect equilibria that are Pareto undominated by any other equilibrium outcome of the stage- $r$ subgame.

\section{Calibration of the STACO Model}

In our setting with heterogeneous players general results on the composition and size of stable coalitions cannot be obtained. Hence, for further analysis we employ a specification of benefits and costs of abatement and a transfer scheme with an empirically meaningful parameter calibration and obtain further insights through numerical simulations. This section explains the calibration of our model which we label STACO-2.2. The model refines STACO 2.1. (Nagashima et al. 2009) in order to examine the impact of renegotiations. Here, we focus on the main features of the model. We consider twelve world regions: USA, Japan (JPN), European Union-15 (EU15), other OECD countries (OOE), Eastern European countries (EET), former Soviet Union (FSU), energy exporting countries (EEX), China (CHN), India (IND), dynamic Asian economies (DAE), Brazil (BRA) and rest of the world (ROW). We account for the benefits of abatement to infinity, but adopt a shorter planning horizon of 100 years, ranging from 2011 to 2110 , for determining abatement paths. In this setting the intertemporal aspects of climate change are well reflected. ${ }^{6}$ Within the planning horizon there are $R$ rounds of renegotiations. This limits the duration of the initial and any further international climate agreement. Below we present empirical results for $R=1,2,3,4,5$ with equal length of stages. Hence for $R=5$, for example, we have renegotiations at $t=1,21,41,61,81$ where coalitions are formed and abatement decisions are taken.

The basic model equations are presented in Box 1. Appendix 2 gives an overview of the model parameters. First we calibrate the benefit function for each region and each period. Benefits from abatement are avoided damages which, in turn, depend on stock of $\mathrm{CO}_{2}$. Damages are derived from the damage cost module of the DICE model (Nordhaus 1994) and the climate module by Germain and Van Steenberghe (2003). The stock of $\mathrm{CO}_{2}$ for each period $M_{t}$ is given in Eq. 6. Stock depends on the stock in the previous period $M_{t-1}$, a natural equilibrium stock $\bar{M}$, a decay rate $\delta$, baseline (or uncontrolled) emissions $\bar{e}_{i, t}$, abatement $q_{i, t}$ and the airborne fraction of emissions that remains in the atmosphere $\omega .{ }^{7}$ We use data for $\mathrm{CO}_{2}$ emissions derived from the EPPA model (Reilly 2005). The damage function is a function of the stock of $\mathrm{CO}_{2}$ and can be approximated by a linear function. In Eq. $7 y_{t}$ denotes global GDP in year $t$. We assume a GDP growth rate of about $2 \%$ annually, using data from the DICE model. Parameters $\gamma_{1}$ and $\gamma_{2}$ are estimated by OLS-regression (Dellink et al. 2004); for the global damage parameter $\gamma_{D}$, we use the estimate by Tol (1997) that damages amount to $2.7 \%$ of GDP for a doubling of $\mathrm{CO}_{2}$ stock over pre-industrial levels. Equation (8) shows the global benefits of abatement depending on stock.

Each region receives a share $\theta_{i}$ of the global benefits, as displayed in Appendix 2, Table 8; see Eq. 9. Benefits are the sum of per-period benefits discounted at rate $\rho$; see Eq. 10. Equation 11 gives the marginal benefits from current abatement (discounted back to period $t$ ).

We specify the abatement cost functions following the estimates of the EPPA model by Ellerman and Decaux (1998). In Eq. $12 \alpha$ and $\beta$ are regional cost parameters. We assume exogenous technological progress which is modelled as a reduction of current abatement

6 Admittedly, we assume that no thresholds or irreversibilities in the climate system are relevant for the time period under consideration.

7 This representation of the carbon cycle is extremely simplified but, as our focus is on the analysis of stability of ICAs, it suffices our needs (cf. Nagashima et al. 2009). 
costs at an annual rate 5 . Equations (13) and (14) specify discounted and marginal abatement costs, respectively.

Based on this specification of benefits and costs, Eq. 15 gives the gross payoff in net present value terms of the stage $r$ abatement game.

For our investigation of the impact of transfers among the regions within a coalition we assume surplus sharing between coalition members; see Weikard et al. (2006) and Nagashima et al. (2009). ${ }^{8}$ As explained in Sect. 2, the coalition maximises its joint payoff in the abatement game. Equilibrium abatement levels are unique (see Appendix 1) and labelled $\boldsymbol{q}_{i, t}^{K^{r}}$. The coalition surplus $S_{t}\left(K^{r}\right)$ Eq. 16 is defined as the joint gain of the coalition members over their joint payoff if no coalition is formed (labelled 'All-Singletons'). The sharing rule assigns a share $\lambda_{i, t} \in[0,1]$ of the coalition surplus $S_{t}\left(K^{r}\right)$ to every coalition member $i \in K$ such that $\sum_{i \in K} \lambda_{i, t}=1$ for all $t$. The shares are proportional to baseline emissions as specified in Eq. 17. ${ }^{9}$ Implementing surplus sharing involves a financial transfer between coalition members. In Eq. 18 stage- $r$ transfers are specified as the benchmark payoff each player receives under All-Singletons plus a share of the coalition surplus accumulated over all stage $r$ periods minus its gross payoff. One of the main advantages of surplus sharing is that individual rationality is always satisfied as long as a coalition is profitable at all, i.e. coalition members will always gain compared to All-Singletons. Note that all transfers are arranged within a given commitment period $r$. Moreover, Eq. 19 states that singletons do not participate in the transfer scheme. Hence, the stage $r$ payoff is given by the gross payoffs from equilibrium abatement plus the transfer; see Eq. 20. Equation (21) gives total payoff for a region where $\psi^{1}$ is the sequence of coalitions $K^{1}, \ldots, K^{R}$.

\section{Results}

This section presents the results from STACO 2.2. We first present, as a benchmark, the oneshot game without renegotiations (Sect. 4.1). We investigate incentives for cooperation and identify which coalitions are stable. Then, we study the effects of renegotiations in a model with a first round of initial negotiations and one round of renegotiations (Sect. 4.2.), and a first round of initial negotiations and several rounds of renegotiations (Sect. 4.3). Section 4.4 examines the impacts of different transfer schemes in the two-stage game.

We identify the equilibria by checking players' incentives to leave or join the coalition for every possible coalition. We are considering only a unique ICA and single deviations.

\subsection{The One-shot Game}

We start by presenting the results for the benchmark case with an initial negotiation and no further renegotiations $(R=1)$. Table 1 gives results for two reference cases, the All-Singletons and the Grand Coalition, and for the only stable and Pareto undominated (renegotiation proof) equilibrium, consisting of USA and China. The All-Singletons case reflects the noncooperative solution where no ICA is signed. It is a Nash equilibrium, but as it is Pareto

\footnotetext{
8 Nagashima et al. (2009) discuss and compare several transfer schemes. Their analysis shows that "optimal transfers", as suggested by e.g. Weikard (2009), would imply larger global abatements than other transfer schemes. It is, however, not trivial how this extends to a setting with multiple commitment periods. How optimal transfers can be designed in a setting with renegotiations is the topic of a companion paper, see Weikard and Dellink (2008).

9 Nagashima et al. (2009) show that a transfer scheme based on the baseline path of emissions outperforms transfers based on a historical base year in terms of stability, global payoffs and abatement.
} 


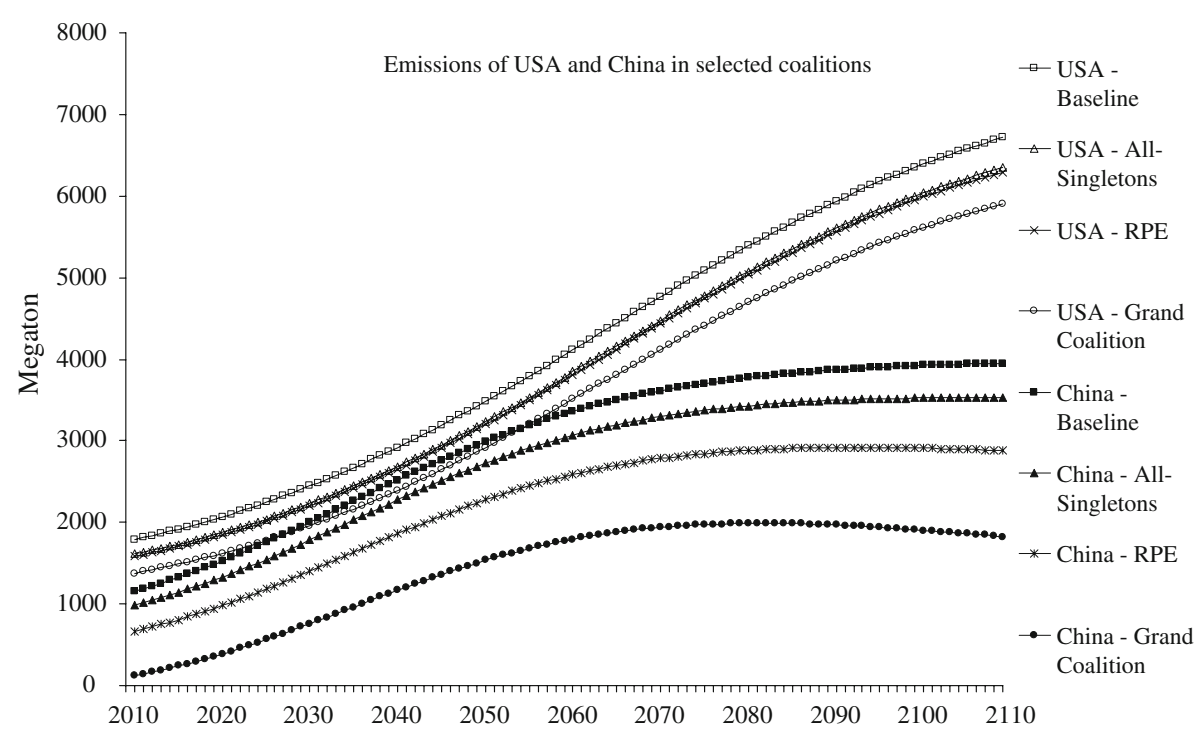

Fig. 1 Emission paths for USA and China-key results for selected coalitions. Note: emissions for USA-All Singletons and USA-RPE almost overlap

dominated by the equilibrium coalition (USA, China), it is not renegotiation proof. The Grand Coalition represents full cooperation. It is not an equilibrium since all regions (except EET, EEX and China) have positive incentives to free-ride (indicated in column 6 of Table 1).

The first observation from Table 1 is that abatement and payoffs differ substantially across regions. Under All-Singletons China abates the most, both in absolute and relative terms, i.e. as percentage of its own baseline emissions. The main beneficiary of the global abatement efforts is the EU-15, as they have the highest marginal benefits from abatement (see Appendix 2 ). This result does not include transfers as under All-Singletons each region bears the full cost of their abatement efforts.

Secondly, the three regions with the lowest marginal abatement costs, China, USA and India, adopt high relative levels of abatement in all coalitions. This reflects the maximisation of regional net benefits in the non-cooperative case. Under cooperation marginal abatement costs are equalised across participating regions. This requires a larger effort by regions with low abatement cost. In all scenarios, the USA remains the largest emitter, even though their abatement levels are high. This reflects the large share of the USA in global emissions of GHGs in the benchmark projection. Global emission levels are increasing over time and a stabilisation of emissions will not occur, not even under the Grand Coalition. Figure 1 shows emissions paths for USA and China for the Baseline, under All-Singletons, the coalition (USA, China; indicated as RPE) and the Grand Coalition.

Thirdly, under All-Singletons the differences in marginal abatement costs (not reported in the table) imply that benefits from cooperation can be reaped. The gains from cooperation are large: the net present value of payoff from abatement of the Grand Coalition increases roughly threefold compared to the non-cooperative case; abatement levels of the Grand Coalition are almost five times larger than All-Singletons abatement. These increased abatement efforts are not in the interest of all regions, however. Though abatement percentages are decreasing over time, especially for quickly growing regions such as China, the huge abatement efforts put on the regions with low marginal abatement costs may be optimal from a global perspective, 


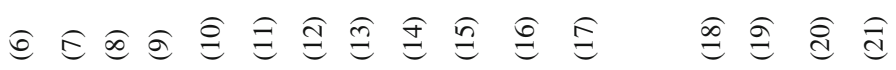

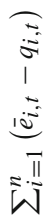

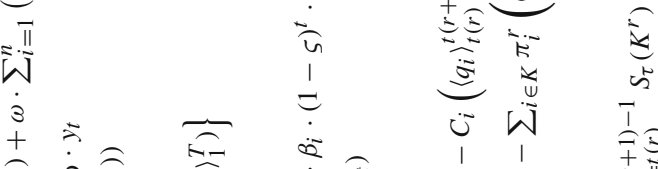

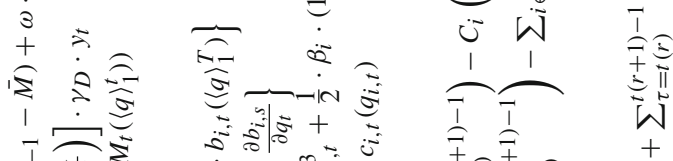

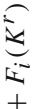

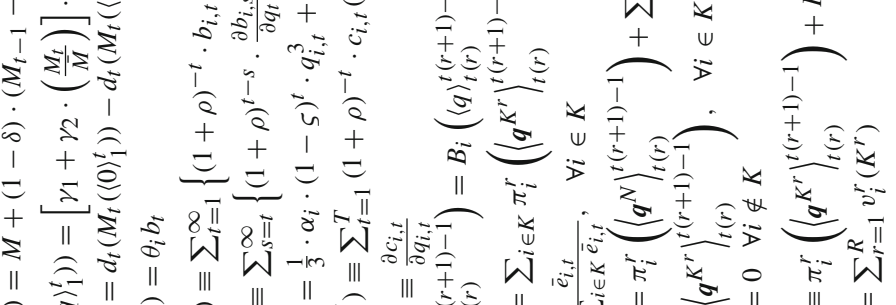

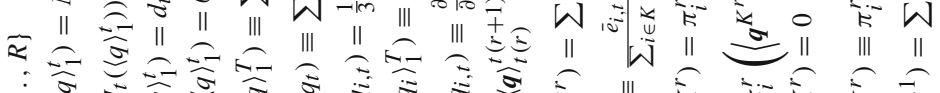

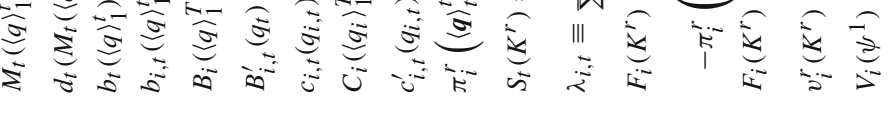

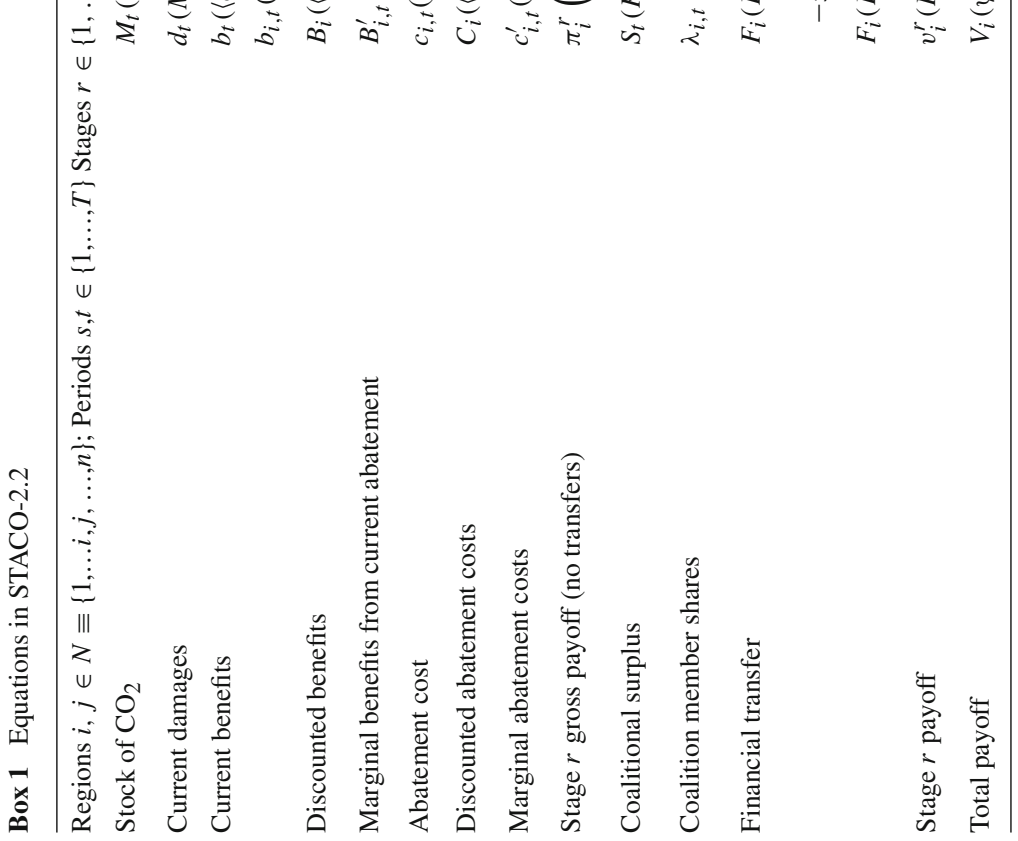




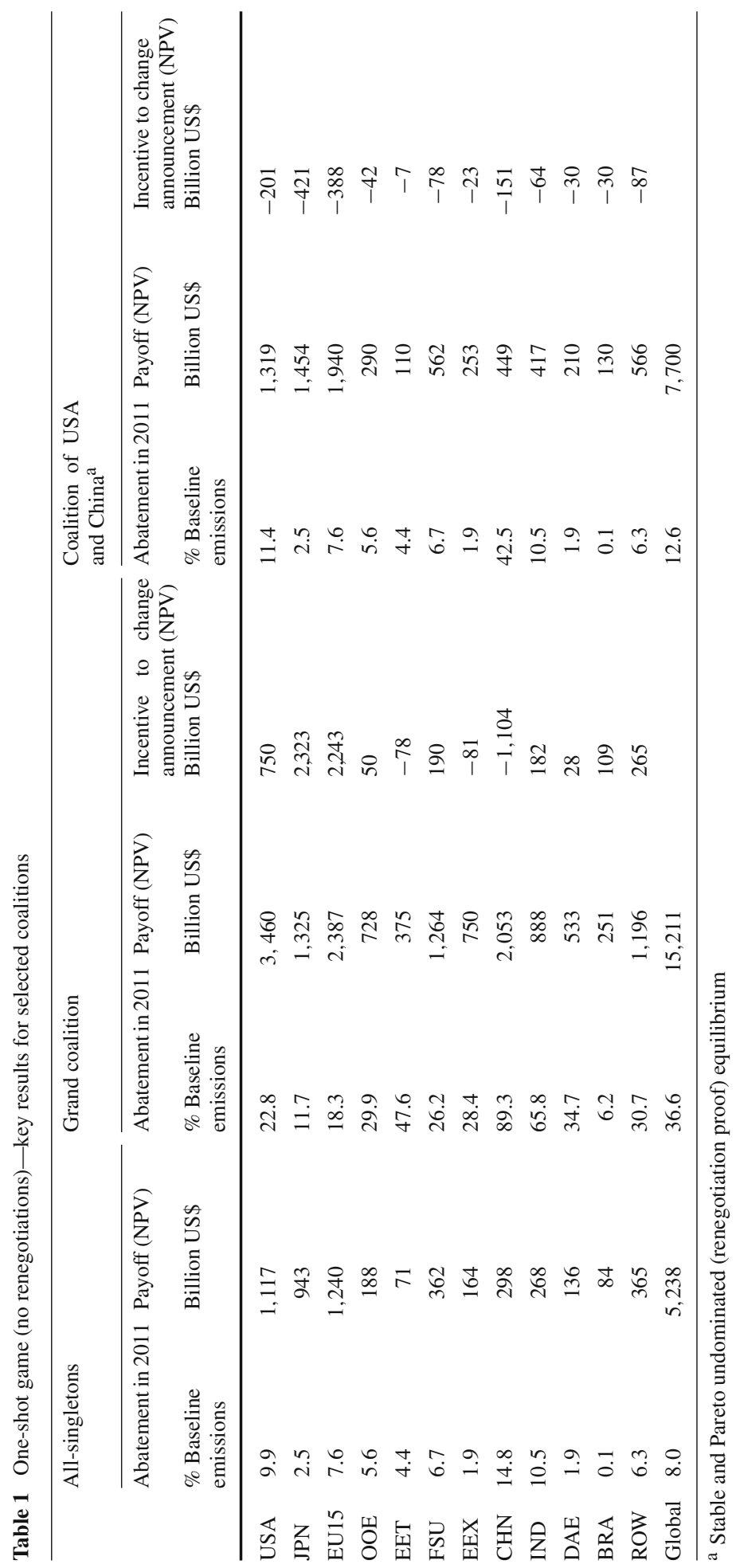


but will not be in the interest of China unless financial compensation by regions that benefit from abatement efforts can be arranged. The compensation payments defined by the surplus sharing rule, however, are so large that Japan and the European Union have strong incentives to leave the Grand Coalition. ${ }^{10}$ The only regions that have no incentive to leave the Grand Coalition are Eastern European Countries (EET), Energy Exporters (EEX) and China; all other 9 regions would be better off when free-riding. This sheds some light on the possibility of issue linking. In order to stabilise the Grand Coalition benefits from cooperation in other fields such as removal of trade barriers, for example, must offset the incentive to change membership for those 9 regions that prefer to leave.

Fourthly, the stable coalition of USA and China improves over the All-Singletons case, both in terms of abatement and payoff. Abatement efforts are larger for the coalition members. Other regions do not change their abatement efforts as they have dominant strategies, given the constant marginal benefits in our specification. All regions do, however, benefit from the additional abatement by the coalition members and thus payoffs are higher than in the All-Singletons case for all regions. In fact, the region that benefits most from this coalition is the European Union, as its benefits increase the most and its abatement costs remain the same as in the All-Singletons case. A large gap remains between the stable coalition (USA, China) and the Grand Coalition and only about $25 \%$ of the potential gains from cooperation can be reaped.

Fifthly, all other possible coalitions violate either internal or external stability. This indicates strong free-rider incentives. All regions benefit from other players' provision of the public good, but have limited incentives to contribute. Only a few coalitions are internally stable and these consist of no more than three regions.

\subsection{Results for the Two-stage Renegotiation Game with Transfers}

When we introduce a renegotiation round, the possibility to change membership between both periods emerges. When more than one RPE arises in the second stage of the game, there are credible possibilities to force regions to cooperate in the first stage (cf. Sect. 2). It turns out that in the two-stage game the equilibria that emerge in the second stage are all dominated by the equilibrium (USA, China). Thus, we have a unique RPE at stage two. Consequently, there are no credible punishment strategies and the same equilibrium arises in the first stage. The RPE of the two-stage game is a sequence of coalitions consisting of USA and China in both stages. As reported in Table 2, this result is robust with respect to the renegotiation time (i.e. whether renegotiations occur after 20, 40, 50, 60 or 80 years), but it is not robust with respect to the frequency of renegotiations as we will show below.

Table 3 offers a closer look at the coalition (USA, China) in the game with two periods of 50 years each. Due to low marginal abatement costs, China will take on a large share of the abatement effort. In percentages, these are especially large in the early years when China's emissions are still relatively low (compare Tables 1 and 3 ). In contrast, the abatement percentage of the USA in 2011 is only a little above the level of the All-Singletons case; cf. Fig. 1. Thus, the main mechanism that governs this result is that China takes the additional benefits in the USA into account and abates more, financed by the USA, similar to the adoption of the Clean Development Mechanism in the Kyoto Protocol.

10 The gross payoff without transfers for these two regions is positive and large in the Grand Coalition. 


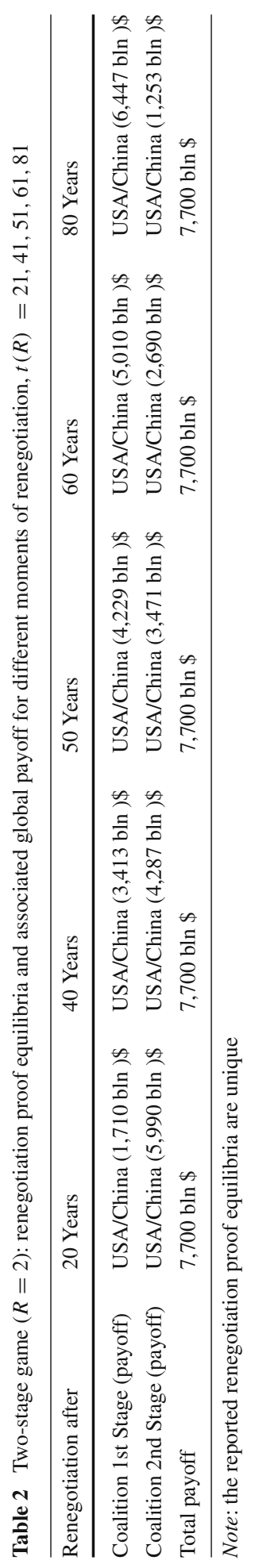


Table 3 Two-stage game $(R=2)$ : key results for the sustained coalition of USA and China in the game with renegotiations after 50 years

\begin{tabular}{|c|c|c|c|c|c|c|c|c|}
\hline & \multicolumn{2}{|l|}{ Abatement } & \multicolumn{2}{|c|}{ Payoff (NPV) } & \multicolumn{2}{|c|}{$\begin{array}{l}\text { Incentive to change } \\
\text { announcement (NPV) }\end{array}$} & \multicolumn{2}{|c|}{$\begin{array}{l}\text { Marginal } \\
\text { abatement cost }\end{array}$} \\
\hline & & & $\begin{array}{l}\text { Billion } \\
\text { US\$ }\end{array}$ & & $\begin{array}{l}\text { Billion } \\
\text { US\$ }\end{array}$ & & US\$/ton & \\
\hline & 2011 & 2061 & 1st Stage & 2nd Stage & 1st Stage & 2nd Stage & 2011 & 2061 \\
\hline USA & 11.4 & 7.5 & 716 & 603 & -109 & -92 & 28.5 & 46.6 \\
\hline JPN & 2.5 & 2.6 & 800 & 654 & -234 & -187 & 17.1 & 27.9 \\
\hline EU15 & 7.6 & 5.7 & 1,067 & 873 & -213 & -175 & 23.4 & 38.1 \\
\hline $\mathrm{OOE}$ & 5.6 & 2.9 & 160 & 131 & -25 & -17 & 3.4 & 5.6 \\
\hline EET & 4.4 & 2.8 & 60 & 49 & -3 & -3 & 1.3 & 2.1 \\
\hline FSU & 6.7 & 5.0 & 309 & 253 & -38 & -40 & 6.7 & 10.9 \\
\hline EEX & 1.9 & 1.7 & 139 & 114 & -12 & -11 & 3.0 & 4.8 \\
\hline CHN & 42.5 & 23.0 & 250 & 199 & -87 & -64 & 28.5 & 46.6 \\
\hline IND & 10.5 & 5.1 & 229 & 187 & -38 & -27 & 4.9 & 8.1 \\
\hline DAE & 1.9 & 1.6 & 116 & 95 & -16 & -14 & 2.5 & 4.0 \\
\hline BRA & 0.1 & 0.1 & 71 & 58 & -16 & -13 & 1.5 & 2.5 \\
\hline ROW & 6.3 & 4.4 & 312 & 255 & -47 & -40 & 6.7 & 11.0 \\
\hline
\end{tabular}

As the same coalition arises in both stages of the game, these results are directly comparable to the RPE in the one-shot game: for instance, the net present value of the payoff of both stages adds up to the payoff in the one-shot game. The differences in regional emissions over time makes the incentive structures different for both stages, but these differences are not decisive and the same renegotiation proof coalition exists in both stages.

Finally, Table 3 shows the marginal abatement costs for each region in 2011 and 2061. Optimality requires that the marginal abatement costs of the coalition members are equal. They are higher than the marginal abatement costs under All-Singletons because coalition members account for the positive externalities accruing to other members. The development of the marginal abatement costs over time is driven by the increase in marginal benefits of abatement in a growing economy. Recall that damages from GHG emissions are a share of global GDP; see Eq. 7. With decreasing marginal abatement costs (for any given abatement level) due to technological progress abatement levels will rise over time.

\subsection{Extensions to Three and More Stages-Increasing the Frequency of Negotiations}

Increasing the frequency of renegotiations may have an impact on the equilibria that emerge in the different stages. With more frequent renegotiations, the stages are shorter. The calculation of payoffs using all future benefits from current abatement (cf. Sect. 3) guarantees that the shorter stages do not lead to myopic behaviour by the players. We expect that increasing the number of renegotiations may enhance stability of larger coalitions in the earlier stages when multiple subgame RPE arise in later stages. In this case, consider the RPE of the stage $r$ subgame that gives the lowest payoff of all RPEs of that subgame to a certain region. This RPE can be used as a threat to enforce the cooperation of that region at the preceding stage $r-1$. 
In fact, once we incorporate multiple rounds of renegotiations $(R>2)$, each with equal length, several renegotiation proof equilibria emerge. The RPEs that perform best in terms of net present value of global payoff aggregated over all stages are reported in Table 4 .

The game with three rounds of negotiations has a unique RPE in the third stage, again consisting of USA and China. In the second stage this RPE is, however, no longer unique. The coalition of EU15 with the Eastern European countries and China emerges as a second equilibrium. Even though it is inferior from a global perspective, it is preferred by all regions except EU15. Hence, it is Pareto undominated. This implies that all regions other than EU15 can be threatened by forming the coalition (USA, China) in the second stage. Thus, a number of RPEs with EU15, EET and China in the second and USA and China in the third stage emerge. In contrast, we find only two equilibria with USA and China in the second stage, as only if EU15 can be punished in this setting. In the 3-stage game an initial announcement of the USA to sign in the second stage if and only if EU15 signs in the first stage is credible. If EU15 would not sign, then the best RPE of the stage-2 subgame for the USA is the coalition (EU15, EET, China) followed by (USA, China) in stage 3. Hence, the USA do not have an incentive to deviate from this punishment strategy.

The 4-stage game leads to similar results as the 3-stage game. In the later part of the century, i.e. in the last two stages, a unique RPE of USA and China exists while there is room for multiple RPEs in the earlier stages and thus a range of equilibria in the first stage. Although the numerical results differ, the incentive mechanism is the same as for the 3-stage game. The uniqueness of the RPE at the stage- 3 subgame (stretching over stages 3 and 4) can be seen as an extended stage 3 . In our setting this implies that the relatively ambitious ICAs that emerge in first commitment period are maintained only for a shorter time (25 years instead of 33 years) and total payoffs over the entire model horizon are slightly lower than in the three-stage game. Hence, more frequent renegotiations do not necessarily lead to better outcomes.

The situation changes when there are five stages in the game, i.e. renegotiations every 20 years. In this case, the coalition of USA and China is again unique in the last two stages of the game, while two RPE arise for the third stage: USA and China or EU15, EET and China. The main difference with the games with fewer stages is that there are now three consecutive stages with multiple RPE. Essentially, the two equilibria in the third stage induce a range of equilibria in the second stage, and thereby the possibilities to set incentives for cooperation in the first stage become much larger.

The equilibria reported in Table 4 are the best performing ones in terms of net present value of global payoff (and given the characteristics of our model also in terms of GHG concentrations). In most cases, these involve coalitions with China, as the marginal abatement costs are lowest in this country. There are, however, in total 1,542 RPEs, with many different coalition members in the first stage. Even some stable 10-player coalitions emerge at the initial stage.

It is worth noting that the Grand Coalition is not stable at any stage, which is hardly surprising as free-rider incentives increase with the number of coalition members. Punishment strategies are insufficient to overcome these in the 5-stage game. At the first stage the best performing RPE achieves $64 \%$ of the gains the Grand Coalition would achieve at that stage but over a century it achieves only $36 \%$ of the gains of the Grand Coalition.

Finally, in Table 5 the incentives to change announcement are given for the best performing RPE in the 5-stage game. These incentives are expressed in net present value, calculated back to 2010, and can, hence, be directly compared. The development of these incentives is a mixture of several mechanisms, including technological progress and increasing emissions and abatement levels over time. 


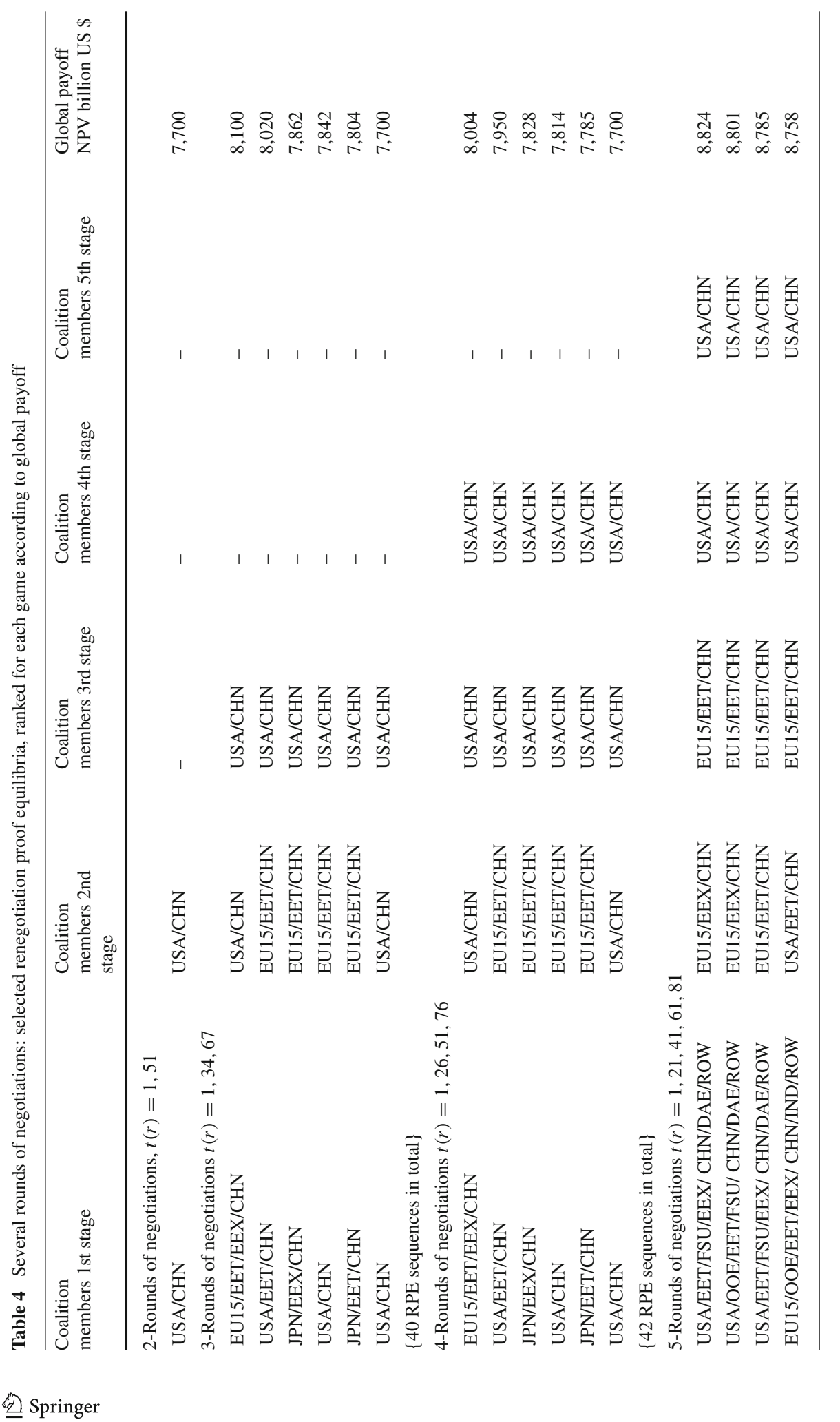




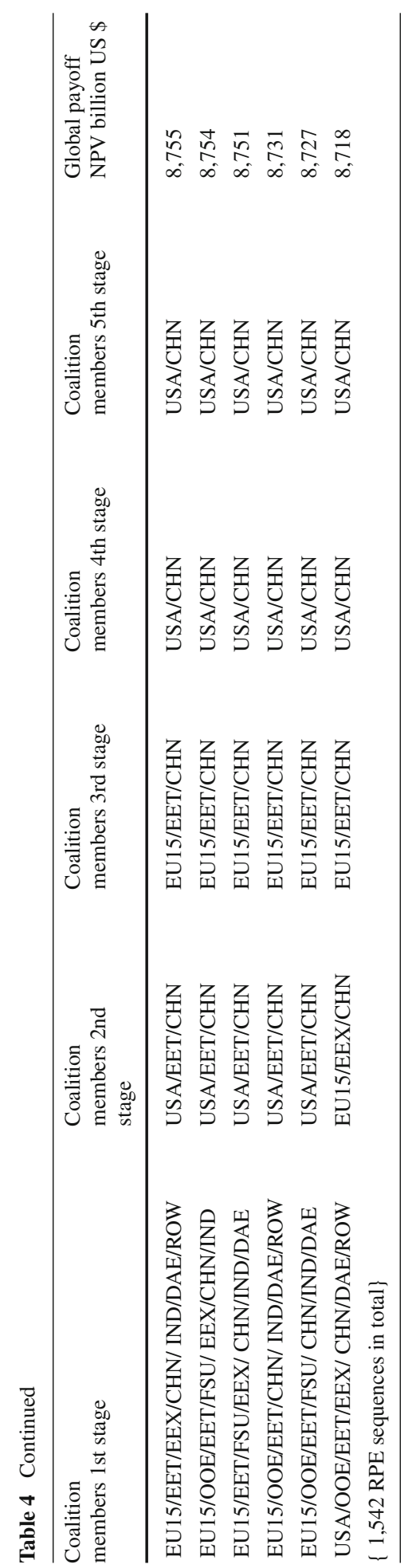


Table 5 Five-stage game: incentives to change announcement (NPV; billion US\$) in the best performing RPE (coalition members in bold)

\begin{tabular}{lrrrrr}
\hline & 1st Stage & 2nd Stage & 3rd Stage & 4th Stage & 5th Stage \\
\hline USA & $\mathbf{8 6}$ & -33 & -19 & $-\mathbf{3 8}$ & $-\mathbf{3 4}$ \\
JPN & -290 & -115 & -97 & -78 & -67 \\
EU15 & -309 & $-\mathbf{5}$ & $-\mathbf{1 6}$ & -73 & -62 \\
OOE & -31 & -8 & -4 & -7 & -6 \\
EET & $\mathbf{3}$ & 1 & $-\mathbf{2}$ & -1 & -1 \\
FSU & $\mathbf{3 7}$ & -12 & -12 & -17 & -15 \\
EEX & $\mathbf{1 1}$ & $-\mathbf{1}$ & 0 & -5 & -4 \\
CHN & $-\mathbf{5 8}$ & $-\mathbf{5 8}$ & $-\mathbf{5 2}$ & $-\mathbf{2 7}$ & $-\mathbf{2 1}$ \\
IND & -54 & -12 & -7 & -11 & -10 \\
DAE & $\mathbf{1 7}$ & -5 & -3 & -6 & -5 \\
BRA & -19 & -7 & -5 & -5 & -5 \\
ROW & $\mathbf{5 0}$ & -16 & -13 & -17 & -14 \\
\hline
\end{tabular}

From the table the impact of the punishment strategies can be clearly seen. In the first stage, 6 out of the 7 coalition members are threatened into collaboration: their incentives to leave the coalition are positive, but smaller than the threat that an inferior coalition is played in later stages. The table also shows that the European Union and Japan are much better off outside the coalition in the first stage than inside.

\subsection{Changing the Transfer Scheme}

Previous studies, including Nagashima et al. (2009), have shown that the transfer scheme adopted can have major impacts on the stability of coalitions. The outcomes of our 2-stage game with a surplus sharing rule are compared with outcomes of transfers resulting from tradable emission permits and with the no-transfers situation. The tradable permit system is interesting as it is part of the Kyoto Protocol. The no-transfers situation serves as a benchmark. In order to keep the analysis comparable across scenarios we assume that the permits are distributed to coalition members according to baseline emissions.

Table 6 shows that the transfer scheme influences the coalition members in the RPE, but in all cases one unique RPE emerges with two coalition members. Introducing a tradable emission permit system as the transfer scheme substantially alters the incentive structures of the regions. Regions with low marginal abatement costs will be able to sell emission permits and thus increase their net benefits, while regions with high marginal abatement costs may want to buy permits. Therefore, EU15, with high marginal benefits and high marginal abatement costs, prefers to trade with China (low marginal abatement costs). EU15 buys emission permits to combine high global abatement efforts with low regional abatement levels, whereas China can gain from selling permits. The USA is a much less attractive partner for China, as the USA has ample opportunities to reduce emissions at low costs domestically. Therefore, the equilibrium permit price in a market consisting of USA and China will be lower.

When no transfer scheme is adopted China can no longer benefit from the transfers, and thus it has no incentives to join a coalition. Consequently, the two regions with the largest incentives to stimulate abatement, Japan and EU15, are forced to cooperate without partners, and as their marginal abatement costs are relatively high, their ambition level is low. The coa- 
Table 6 Influence of the transfer scheme on the Renegotiation Proof Equilibria

\begin{tabular}{lllcc}
\hline & RPE 1st stage & RPE 2nd stage & $\begin{array}{l}\text { NPV of global } \\
\text { payoff (bln\$) }\end{array}$ & $\begin{array}{l}\text { Concentrations in } \\
2110 \text { (Gton) }\end{array}$ \\
\hline Surplus sharing (base case) & USA, China & USA, China & 7,700 & 1,425 \\
Tradable permits & EU-15, China & EU-15, China & 7,667 & 1,425 \\
No transfers & Japan, EU-15 & Japan, EU-15 & 5,486 & 1,445 \\
\hline
\end{tabular}

Note: Each simulation generates one unique Renegotiation Proof Equilibrium

lition of Japan and EU15 hardly improves the global payoff compared to the non-cooperative outcome.

\section{Discussion and Conclusions}

In this final section we would like to turn to the policy implications of our findings. Before we do so we summarise the main findings and we discuss some limitations of our modelling approach.

This paper develops a framework to determine the RPE coalitions in a dynamic model of coalition formation. In order to gain a better understanding of international climate agreements we consider heterogeneous players, reflecting the differences of marginal benefits and costs of abatement between regions. Coalition formation helps to exploit low cost abatement options in some regions. We focus on the impacts of renegotiations on the stability of international climate agreements in a setting of asymmetric countries explicitly including the option of transfers among coalition members. Because a full analytical analysis of stability with asymmetric regions and renegotiations is so far impeded by the complexity of the situation, we develop a dynamic version of the STACO model (STACO 2.2) that comprises costs and benefits of greenhouse gas abatement for 12 world regions and allows for renegotiations and transfers. We apply a numerical analysis to test whether coalitions are renegotiation proof in a number of settings.

We find that in the absence of transfers renegotiations do not lead to large or ambitious coalitions. In a setting with transfers and with a limited number of renegotiations we find a unique RPE, the coalition of the USA and China. More interesting are the results for scenarios with a larger number of rounds of renegotiations. We find multiple renegotiation proof equilibria with more ambitious ICAs in early stages of the game. In the later stages only the coalition of the USA and China survives as an equilibrium of the subgame. The general pattern-large coalitions initially, but small coalitions later-concurs with the findings of Rubio and Ulph (2007). However, what drives this result is quite different in our setting. Rubio and Ulph study a difference game with identical players, an infinite time horizon, a stock pollutant and a convex damage function. Because players are assumed to be identical, only the number, not the identity, of coalition members matters for the development of the stock of the pollutant. Rubio and Ulph use a "random assignment rule" to determine which player is a member at any given stage. This rules out the use of punishment schemes. Their result, declining membership over time, is entirely driven by an increase of the stock of the pollutant over time which implies increasing marginal damages and, hence, increasing 
(potential) gains from cooperation and increasing free-rider incentives. ${ }^{11}$ In our case the decline of participation and abatement over time is driven by declining threats. With a finite time horizon-reflecting finite fossil fuel reserves - there is no credible threat of punishment at the last stage. The stability of larger coalitions at an early stage is driven by the existence of multiple equilibria of the relevant subgame that can serve as credible threats.

Turning now to the limitations of our analysis we would like to mention four major issues. The first two issues concern the rules of the game, the third concerns the solution concept and the fourth is more policy oriented. First, notice that we obtain results for a given transfer rule-surplus sharing proportional to baseline emissions. Transfers are limited to coalition members and are arranged within a given commitment period. We do not explore in this paper how a transfer scheme may emerge from the negotiation process and we not explore how transfers can be used to create incentives for coalition membership. The former can be addressed in a bargaining framework, cf. Caparrós et al. (2004). The latter is explored in a companion paper to this paper, cf. Weikard and Dellink (2008).

Second, the rules of our game do not allow for the co-existence of multiple coalitions. A full numerical analysis of all possible multi-coalition structures with several rounds of renegotiations is practically impossible due to combinatorial complexity. The case where two agreements coexist has been explored by Asheim et al. (2006). Their finding is that global abatement levels would be higher with two regional agreements in place of one global agreement. The challenge for future research is to push forward model analyses that are rich enough to capture the main options available in climate policy-making, such as regional agreements and well-designed transfer schemes, while maintaining analytical tractability. Clearly, "small" analytical models and "large" integrated assessment models must complement each other.

Third, and related to the previous issue, we employ a refined Nash equilibrium as a solution concept. The refinements, subgame perfectness and renegotiation proofness, maintain the presumption that players consider deviations always individually, never collectively. Of course, in climate politics there is nothing that rules out collective action of various groups of countries such as e.g. the collaboration of G77 and China.

Fourth, in our model there is no cost of leaving the ICA. In practice a country that joins makes a political commitment. Typically, leaving the ICA would involve a cost and this would support internal stability of any ICA.

Given the limitations of our scenario analysis, conclusions for climate policies must be drawn with care. We can however point to a number of insights from our study. The first is, of course, that the prospect of renegotiation matters. In our setting, future play offers options to impose threats that set incentives to join an ICA at an earlier stage. Many studies have argued that effective climate coalitions will not be stable (e.g. Barrett 1994; Finus et al. 2006; Altamirano-Cabrera and Finus 2006). Our analysis shows that with heterogeneous players and a transfer scheme that shares the gains from cooperation it is possible to exploit some of the low cost abatement options. This fact, in combination with additional incentives that emerge from credible threats under renegotiations leads to ICAs that can capture $36 \%$ of the potential gains from cooperation over a century, with $64 \%$ of the potential gains of the first stage in our model with five renegotiation stages. These results are far less bleak than what is suggested in the literature on self-enforcing environmental agreements. Moreover, even better results seem to be possible if the transfer scheme is specifically designed to stimulate membership and if multiple agreements are considered.

11 It is well-known in the literature on international environmental agreements that gains from cooperation are coupled with free-rider incentives, cf. Barrett (1994). 
The inspection of our results suggests that more frequent negotiations generate a larger number of equilibria that can be used to set incentives. Although this is generally true, there is a drawback. More frequent negotiations do not necessarily lead to more effective agreements. Although threats are larger with more frequent negotiations, the corresponding commitment periods are shorter. The gains from stabilising a larger coalition (if there is any) can be captured only for a shorter period. This can be seen when comparing 3 rounds with 4 rounds of negotiation (see Table 4).

Furthermore, in our applied setting we find powerful incentives for the EU15 and USA to exploit the prospect of renegotiations strategically and coerce cooperative behaviour of the other (while free-riding themselves). Such strategic possibilities will only be temporary, however, as the incentives to cooperate change with every round of renegotiation.

The bottom line of our analysis is that a clear prospect for future renegotiations may help to bring about an early effective agreement.

Acknowledgement An earlier version of this paper was presented at the Third World Congress of Environmental and Resource Economists, July 3-6, 2006, Kyoto, Japan. We gratefully acknowledge the support of our collaborators in the STACO project.

Open Access This article is distributed under the terms of the Creative Commons Attribution Noncommercial License which permits any noncommercial use, distribution, and reproduction in any medium, provided the original author(s) and source are credited.

\section{Appendix 1}

Each stage game of our greenhouse renegotiation game explained in Sect. 2 consists of a coalition formation game and a GHG abatement game. Here we show that the latter has a unique interior solution under STACO specifications (see Box 1). The GHG abatement game is a difference game where each player fixes a sequence of abatement levels for the relevant renegotiation period. Hence, we consider the abatement levels $q_{i, t}$ for each player $i$ at each time $t$, with $t(r) \leq t<t(r+1)$. First notice that the abatement game is played by the coalition (acting as one player) and $|N|-|K|$ other players. Each player chooses an abatement path $\left\langle q_{i}\right\rangle_{t(r)}^{t(r+1)-1}$ which is a best response to other players' abatement paths. In the STACO specification, according to Eqs. 6 and 7, the stock of GHGs is linear in abatement and damages are linear in stock of GHGs. Therefore, marginal benefits Eq. 11 do not depend on others' abatement, i.e. each player has a dominant strategy. Along an optimal abatement path it must hold that discounted marginal benefits from current abatement equal discounted marginal abatement cost from current abatement at any time $t$, i.e.

$$
(1+\rho)^{-t} \cdot B_{i, t}^{\prime}\left(q_{t}\right)=(1+\rho)^{-t} \cdot C_{i, t}^{\prime}\left(q_{i, t}\right) .
$$

Furthermore, we have $C_{i, t}^{\prime}(0)=0$ while $B_{i, t}^{\prime}>0$ for all $q_{i, t} \in\left[0, \bar{e}_{i, t}\right]$ and $C_{i, t}^{\prime}\left(\bar{e}_{i, t}\right)>$ $B_{i, t}^{\prime}\left(\bar{e}_{i, t}\right)$. Together with the strict convexity of the abatement cost function this guarantees a unique interior solution.

\section{Appendix 2}

See Tables 7 and 8 . 


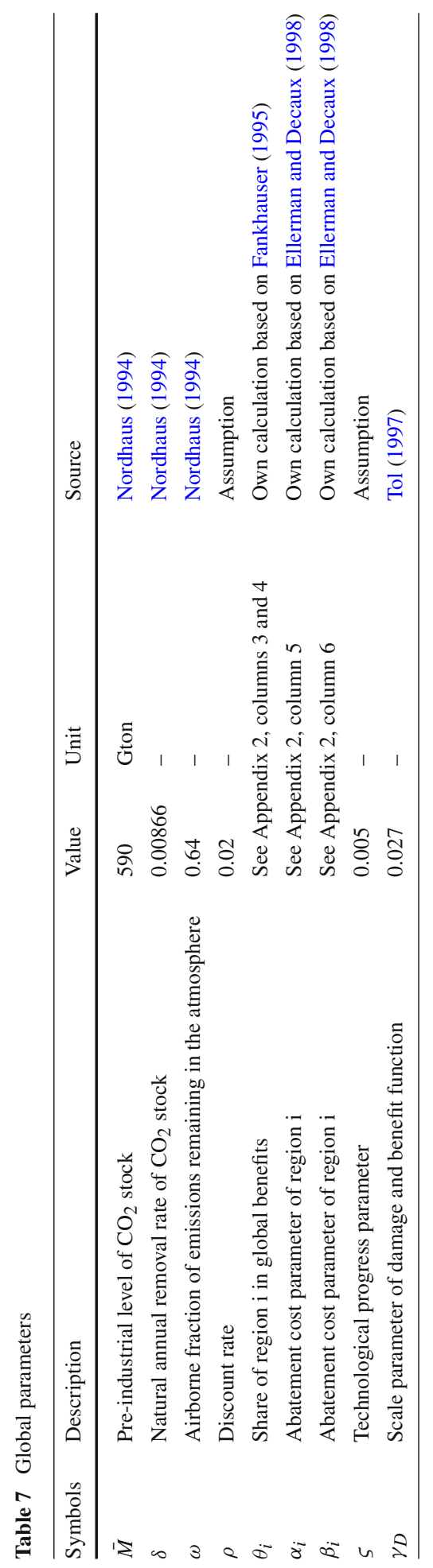


Table 8 Regional parameters in the benefit and abatement cost function

\begin{tabular}{lllll}
\hline Regions & $\begin{array}{l}\text { Emission } \\
\text { in 2010 } \\
\text { Gton (share) }\end{array}$ & $\begin{array}{l}\text { Share of global } \\
\text { benefits calibration I } \\
\theta_{i}\end{array}$ & $\begin{array}{l}\text { Parameter of } \\
\text { abatement cost } \\
\alpha_{i}\end{array}$ & $\begin{array}{l}\text { Parameter of } \\
\text { abatement cost } \\
\beta_{i}\end{array}$ \\
\hline USA & $1.763(0.238)$ & 0.226 & 0.0005 & 0.0398 \\
JPN & $0.344(0.046)$ & 0.173 & 0.0155 & 1.8160 \\
EU15 & $0.943(0.127)$ & 0.236 & 0.0024 & 0.1503 \\
OOE & $0.360(0.049)$ & 0.035 & 0.0083 & 0 \\
EET & $0.226(0.030)$ & 0.013 & 0.0079 & 0.0486 \\
FSU & $0.774(0.104)$ & 0.068 & 0.0023 & 0.0042 \\
EEX & $0.469(0.063)$ & 0.030 & 0.0032 & 0.3029 \\
CHN & $1.127(0.152)$ & 0.062 & 0.00007 & 0.0239 \\
IND & $0.344(0.046)$ & 0.050 & 0.0015 & 0.0787 \\
DAE & $0.316(0.043)$ & 0.025 & 0.0047 & 0.3774 \\
BRA & $0.122(0.016)$ & 0.015 & 0.5612 & 8.4974 \\
ROW & $0.637(0.086)$ & 0.068 & 0.0021 & 0.0805 \\
World & $7.425(\Sigma=1)$ & $(\Sigma=1)$ & & \\
\hline
\end{tabular}

\section{References}

Altamirano-Cabrera J-C, Finus M (2006) Permit trading and stability of international climate agreements. J Appl Econ 9:19-47

Asheim GB, Bretteville Froyn C, Hovi J, Menz FC (2006) Regional versus global cooperation for climate control. J Environ Econ Manage 51:93-109

Babiker MH (2001) The CO2 abatement game: costs, incentives, and the enforceability of a sub-global coalition. J Econ Dyn Control 25:1-34

Barrett S (1994) Self-enforcing international environmental agreements. Oxf Econ Pap 46:878-894

Barrett S (1999) A theory of full international cooperation. J Theor Polit 11(4):519-541

Bernheim BD, Ray D (1989) Collective dynamic consistency in repeated games. Games Econ Behav 1: 295-326

Bernheim BD, Peleg B, Whinston MD (1987) Coalition-proof Nash equilibria I. Concepts. J Econ Theor 42:1-12

Botteon M, Carraro C (1997) Burden-sharing and coalition stability in environmental negotiations with asymmetric countries. In: Carraro C (ed) International environmental negotiations: strategic policy issues. Edward Elgar, Cheltenham pp 26-55

Caparrós A, Pereau J-C, Tazdaït T (2004) North-south climate change negotiations: a sequential game with asymmetric information. Public Choice 121(3-4):455-480

Carraro C, Siniscalco D (1993) Strategies for international protection of the environment. J Public Econ 52:309-328

Chander P, Tulkens H (1995) A core-theoretic solution for the design of cooperative agreements on transfrontier pollution. Int Tax Public Finance 2:279-293

Ciscar JC, Soria A (2002) Prospective analysis of beyond Kyoto climate policy: a sequential game framework. Energy Policy 30:1327-1335

d'Aspremont C, Jaquemin A, Gabszewicz JJ, Weymark JA (1983) On the stability of collusive price leadership. Can J Econ 16(1):17-25

Dellink RB, Altamirano-Cabrera J-C, Finus M, van Ierland EC, Ruijs A, Weikard H-P (2004) Empirical background paper of the STACO model, mimeo, Wageningen University

Dellink RB, Finus M, Olieman N (2008) The stability likelihood of an international environmental agreement. Environ Resour Econ 39:357-377

De Zeeuw A (2008) Dynamic effects on the stability of international environmental agreements. J Environ Econ Manage 55:163-174 
Ellerman AD, Decaux A (1998) Analysis of post-Kyoto CO2 emissions trading using marginal abatement curves. Joint program on the science and policy of global change Report 40, MIT, Cambridge

Eyckmans J, Tulkens H (2003) Simulating coalitionally stable burden sharing agreements for the climate change problem. Resour Energy Econ 25:299-327

Fankhauser S (1995) Valuing climate change. Earthscan, London

Farrell J, Maskin E (1989) Renegotiation in repeated games. Games Econ Behav 1:327-360

Finus M, Rundshagen B (1998) Renegotiation-proof equilibria in a global emission game when players are impatient. Environ Resour Econ 12:275-306

Finus M, van Ierland EC, Dellink RB (2006) Stability of climate coalitions in a cartel formation game. Econ Gov 7:271-291

Fudenberg D, Maskin E (1986) The folk theorem in repeated games with discounting or with incomplete information. Econometrica 54:533-554

Germain M, Van Steenberghe V (2003) Constraining equitable allocations of tradable CO2 emission quotas by acceptability. Environ Resour Econ 26:469-492

Germain M, Toint P, Tulkens H, de Zeeuw A (2003) Transfers to sustain dynamic core-theoretic cooperation in international stock pollutant control. J Econ Dyn Control 28:79-99

Hoel M (1992) International environmental conventions: the case of uniform reductions of emissions. Environ Resour Econ 2:141-159

Kolstad CD (2007) Systematic uncertainty in self-enforcing international environmental agreements. J Environ Econ Manage 53: 68-79

McGinty M (2007) International environmental agreements among asymmetric nations. Oxf Econ Pap 59: 45-62

Na S, Shin HS (1998) International environmental agreements under uncertainty. Oxf Econ Pap 50:173-185

Nagashima M, Dellink RB, van Ierland EC, Weikard H-P (2009) Stability of international climate coalitionsa comparison of transfer schemes. Ecol Econ 68:1476-1487

Nordhaus WD (1994) Managing the global commons: the economics of climate change. MIT Press, Cambridge, MA

Reilly J-M (2005) Emission paths in the MIT-EPPA model, personal communication

Rubio SJ, Ulph A (2002) A simple dynamic model of international environmental agreements with a stock pollutant. Discussion paper in economics and econometrics 0209, Department of Economics, University of Southampton

Rubio SJ, Ulph A (2007) An infinite horizon model of dynamic membership of international environmental agreements. J Environ Econ Manage 54:296-310

Sáiz ME, Hendrix EMT, Olieman NJ (2006) On the computation of stability in multiple coalition formation games. Comput Econ 28:251-275

Tol RSJ (1997) A decision-analytic treatise of the enhanced greenhouse effect. Ph.D. thesis, Vrije Universiteit, Amsterdam

Ulph A (2004) Stable international environmental agreements with a stock pollutant, uncertainty and learning. J Risk Uncertain 29:53-73

Weikard H-P (2009) Cartel stability under an optimal sharing rule. Manchester Sch 77(5):599-616

Weikard H-P, Dellink RB (2008) Sticks and carrots for the design of climate agreements with renegotiations. FEEM working paper 26.2008. Venice, Itlay

Weikard H-P, Finus M, Altamirano-Cabrera J-C (2006) The impact of surplus sharing on the stability of international climate agreements. Oxf Econ Pap 58:209-232 